\title{
Inverting Sediment Bedforms for Exploring the Hazard of Volcanic Density Currents Directly in the Field
}

Pierfrancesco Dellino ( $\nabla$ pierfrancesco.dellino@uniba.it )

University of Bari Aldo Moro

Fabio Dioguardi

British Geological Survey

Roberto Sulpizio

University of Bari Aldo Moro

Daniela Mele

University of Bari Aldo Moro

\section{Research Article}

Keywords: Pyroclastic density, sediment bedforms, hazard of volcanic density, currents, wavelength and grain size

Posted Date: August 9th, 2021

DOl: https://doi.org/10.21203/rs.3.rs-777070/v1

License: (9) This work is licensed under a Creative Commons Attribution 4.0 International License. Read Full License 
1 Inverting sediment bedforms for exploring the hazard of volcanic density currents directly in the field

3 Pierfrancesco Dellino $^{1 *}$, Fabio Dioguardi $^{2}$, Roberto Sulpizio $^{1} \&$ Daniela Mele $^{1}$

$4 \quad{ }^{1}$ Dipartimento Di Scienze Della Terra E Geoambientali, Università Di Bari, Bari, Italy. ${ }^{2}$ British Geological Survey, The 5 Lyell Centre, Edinburgh, UK.

\section{Abstract}

Pyroclastic density currents are ground hugging gas-particle flows moving at high speed down the

9 volcano slope. They are among the most hazardous events of explosive volcanism, causing devastation and deaths ${ }^{1,2}$. Because of the hostile nature they cannot be analyzed directly and most of their fluid dynamic behavior is reconstructed by the deposits left in the geological record, which frequently show peculiar structures such as bedforms of the types of ripples and dunes ${ }^{3,4}$. In this paper, we simplify a set of equations that link flow behavior to particle motion and deposition. This allows, for the first time, the build up of a phase diagram by which the hazard of dilute pyroclastic density currents can be explored easily and quickly by inverting bedforms wavelength and grain size.

\section{Main}

Geologists and engineers have always been fascinated by sediment bedforms. They are a natural beauty of practical importance and represent a primary resource in the reconstruction of ancient sedimentary environments ${ }^{5}$. They form both in fluviatile currents, turbiditic flows, snow avalanches and volcanic pyroclastic density currents (PDCs). When a current flowing over sediment exceeds the critical shear stress for motion, bedforms develop as a result of the interaction between sediment and fluid ${ }^{6}$. The first bedforms to develop are current ripples, which have wavelengths, $W_{l}$, smaller than $60 \mathrm{~cm}^{6}$. Larger bedforms are called dunes ${ }^{7}$. It is widely recognized that the occurrence of ripples or dunes depends on hydrodynamic conditions and sediment characteristics. These are defined in phase diagrams ${ }^{8,9}$ where bedform characteristics as $W_{l}$ and sediment median size, $D$, are 
27 related to flow parameters such as the densiometric Froude number $F r^{\prime 10}$ and the critical Shields number $\theta_{t}{ }^{11}$. For symbols see table1.

$29 \quad F r^{\prime}=\frac{V}{\sqrt{g^{\prime} H}}$ is a balance between inertial and gravitational effects, with $g^{\prime}=g\left(\frac{\rho_{m i x}-\rho_{f}}{\rho_{f}}\right)$

30 31 depth.

32

33

34

35

36

37

38

39

40

41

42

43

44

45

46

47

48

49

representing the reduced gravity, $g$ the gravity acceleration, $V$ the current velocity, $H$ the current

$\rho_{\text {mix }}=\rho_{s} C+\rho_{f}(1-C)(1)$

is the density of the fluid-particle mixture with $\rho_{s}$ particle density, $\rho_{f}$ fluid density and $C$ particle volumetric concentration.

$\theta_{t}=\frac{\rho_{\text {mix }} u_{*}^{2}}{D g\left(\rho_{s}-\rho_{m i x}\right)}(2)$

is the threshold of initiation of motion of particles resting on the substrate and is a form of shear stress ( $\tau=\rho_{\text {mix }} u_{*}^{2}$, where $u_{*}$ is the shear velocity) normalized to the sediment static load. It is a function of the Reynolds' number of shear:

$R e_{*}=\frac{\rho_{\text {mix }} u_{*} D}{\mu}(3)$

where $\mu$ is fluid viscosity.

PDCs form upon explosive eruptions when gases, fragments of magma and lithics, ranging in size from ash to blocks and bombs, are forced throughout the crater to form vertical eruption columns that collapse on the ground or are generated from gravitational failure of domes. They form flows that may spread around the volcano for many kilometers, causing devastation and death. The hazard potential of PDCs depends on impact parameters such as dynamic pressure ${ }^{12}$ :

$$
P_{d y n}=\frac{1}{2} \rho_{m i x} V^{2}(4)
$$

that contrasts the resistance of buildings to the flow ${ }^{13}$, and the volumetric concentration of ash particles $C$, which represents a distinct source of hazard especially far from the volcano where the flow mechanical strength decays, but the current is still rich of ash in suspension. In fact, volcanic 
ash in the air is very harmful to breath ${ }^{14}$, even at temperatures lower than $200^{\circ} \mathrm{C}$ (that are typical of dilute PDCs), and can cause serious health issues and possibly death to a human being if flow duration, $t$, which is a proxy for exposure time, is longer than a couple of minutes ${ }^{14,15}$.

Because of the very hostile nature, the behavior of PDCs is difficult to analyze directly, and our

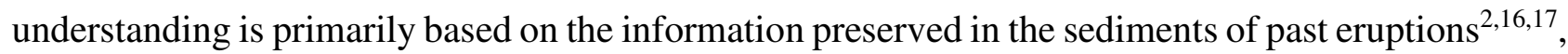
laboratory to large-scale experiments ${ }^{18,19,20}$ and numerical modelling ${ }^{21,22}$. All three methodologies are valid, particularly when they are integrated ${ }^{23}$. The former, though, has the advantage of being directly linked to the ground truth when direct observations of the PDCs are not available, provided valid sedimentological models linking deposit characteristics to flow properties and their impact exist ${ }^{18}$. Bedforms of the types of dunes and ripples have been widely recognized in the deposits of dilute PDCs since the pioneering observations of Richards ${ }^{24}$, Moore ${ }^{25}$ and Fisher and Waters ${ }^{26}$. Further details on other types of bedforms are nowadays emerging from observation of recent eruptions ${ }^{27}$. Differently from what has been done for fluviatile and turbiditic currents, only very few attempts have been made to construct phase diagrams defining the stability fields of bedforms as a function of PDCs flow regimes. Only very recently Smith et al. ${ }^{17}$ have proposed a phase diagram for highly concentrated volcanic granular currents. Dellino et al. ${ }^{28}$, basing on results of large-scale experiments, have proposed a phase diagram in which volcanic deposits are classified based on their sedimentation rate, $S_{r}$ and bedload transportation rate, $Q_{b}$. This agrees with the approach used in the field of sedimentary currents, for which it is widely recognized that the proportion of bedload to suspended load and the sediment size are the major controlling factors on bedforms formation ${ }^{9}$.

$S_{r}$ is defined by Dellino et al. ${ }^{29}$, as:

$S_{r}=\left(\sum_{i}^{n} \rho_{s_{i}} w_{t_{i}}\left(\frac{\frac{\phi_{i} / \rho_{s_{i}}}{\sum_{i=1}^{n} \phi_{i} / \rho_{s_{i}}} * C}{\left(\left(10.065 * \frac{P_{n i}}{P_{n}^{*}}\right)+0.1579\right)} * 0.7+\frac{\frac{\phi_{i+1} / \rho_{S_{i}+1}}{\sum_{i=1}^{n} \phi_{i+1} / \rho_{s_{i+1}}} * C}{\left(\left(10.065 * \frac{P_{n i}}{P_{n}^{*}}\right)+0.1579\right)} * 0.3\right)\right)-0.01(5)$ with the subscript $i$ referring to the $i_{t h}$ particle-size class and $n$ being the number of size classes of the grain-size distribution of the sediment, where $P_{n i}=w_{t i} / k u *$ is the Rouse number of the $i_{t h}$ size fraction of the solid material suspended in the current, with $k$ the Von Karman constant $(0.4)$ and $w_{t i}$ the 
terminal velocity of the $i_{\text {th }}$ size fraction. $P_{n}{ }^{*}=P_{\text {navg }} / P_{n s u s p}$ is the normalized Rouse number of the current, i.e. the ratio between the average Rouse number of the solid material in the current and the Rouse number at maximum suspension capacity. $\phi_{i}, \rho_{s_{i}}$ and $P_{n i}$ are the weight fraction, the density and the Rouse number of the $i_{t h}$ grain-size fraction, respectively. The sedimentation rate was transformed in the sedimentation rate per unit width, $S_{r w}$ in order to make it comparable with $Q_{b}$ dimension ${ }^{28}$.

$Q_{b}$ is defined by Dellino et al. ${ }^{28}$ (modified from Wilcock and Crowe ${ }^{30}$ ) as:

$Q_{b}=\sum_{i}^{n} q_{b i}(6)$

where

$q_{b i}=\frac{\left(\rho_{s} / \rho_{m i x}-1\right) g q_{b i}}{W_{i}^{*} \phi_{i} u_{*}^{3}}$ and $W_{i}^{*}=\left\{\begin{array}{c}0.002 \xi^{7.5} \text { for } \xi<1.35 \\ 14\left(1-\frac{0.894}{\xi^{0.5}}\right) \text { for } \xi \geq 1.35\end{array}\right.$

$q_{b i}$ is the volumetric bedload transport rate of the $i_{t h}$ size fraction per unit width of the flow, and $\xi=$ $\tau / \tau_{r i}$ is the normalized shear stress, where $\tau_{r i}$ is the minimum shear stress needed to move the $i_{t h}$ size fraction at bedload.

The lower right portion of the $S_{r w}$ vs $Q_{b}$ phase diagram of Dellino et al. ${ }^{28}$ represents the field of massive deposits due to highly concentrated flows, also known as pyroclastic flows. The upper portion of the diagram represents the field of stratified deposits with ripple and dune bedforms, which are related to highly expanded, fast-moving, dilute and turbulent PDCs. $W_{l}$ of bedforms that characterize dilute PDCs, shown in the diagram as the distance between two successive dunes or ripples (in $\mathrm{cm}$ ), is inversely proportional to the $S_{r w} / Q_{b}$ ratio, with ripples having a ratio larger than 0.05 and dunes smaller than 0.05 .

In this paper, we further populate the diagram in the portion of dilute PDCs by adding 88 points relative to various eruptions of Vesuvius, Campi Flegrei and Vulcano in Italy. With this addition, the new dataset consists of 98 deposits (Fig. 1) and covers a wide span of the $S_{r w}$ vs $Q_{b}$ space, allowing 


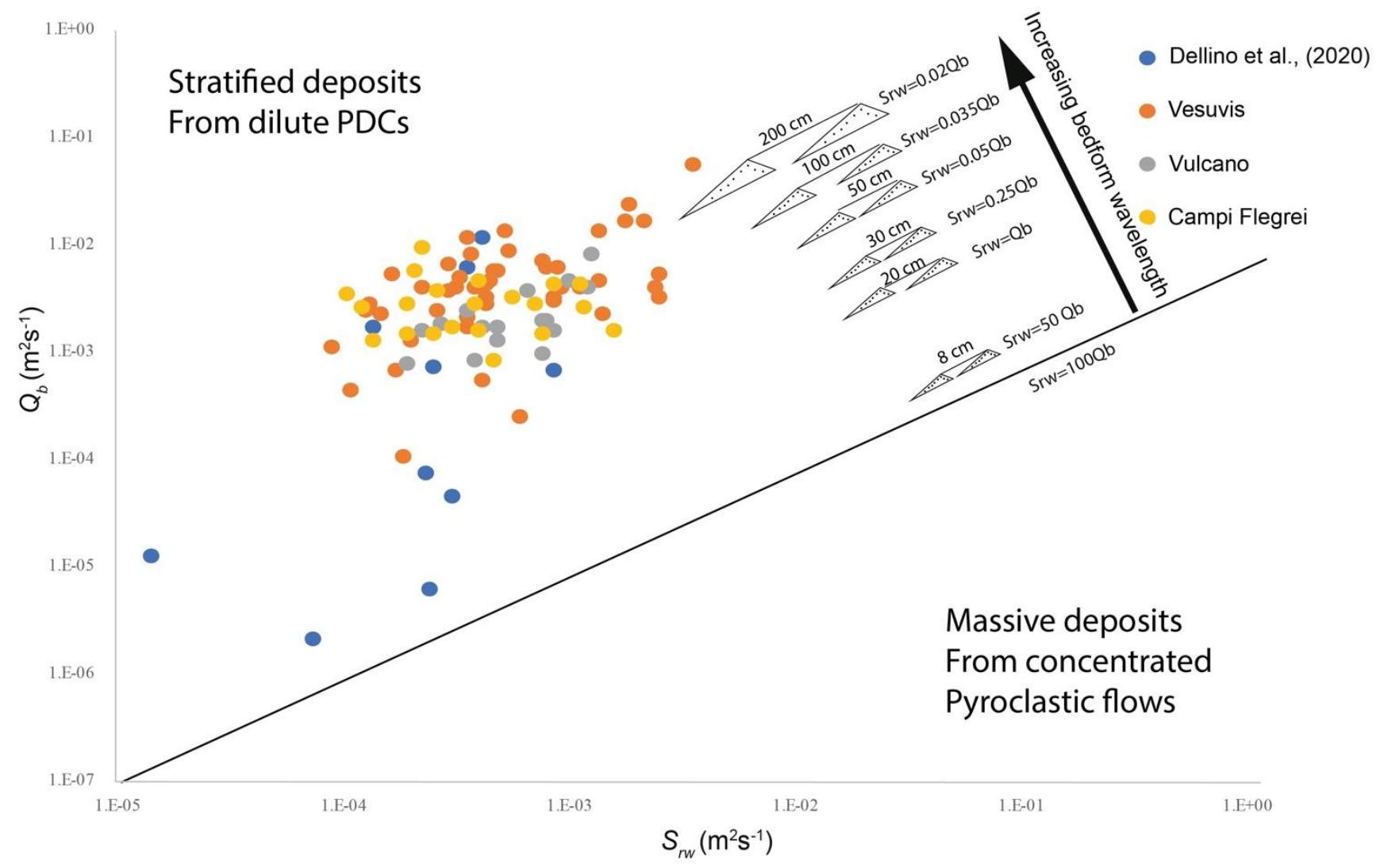

Fig.1. $S_{r w} v s Q_{b}$ diagram in which 88 points have been added to those of Dellino et al. ${ }^{28}$. The $W_{l}$ of bedforms as a function

The bedform $W_{l}$ ranges from ripples (Fig. 2a), starting at $10 \mathrm{~cm}$, to dunes (Fig. 2b), up to $250 \mathrm{~cm}$.
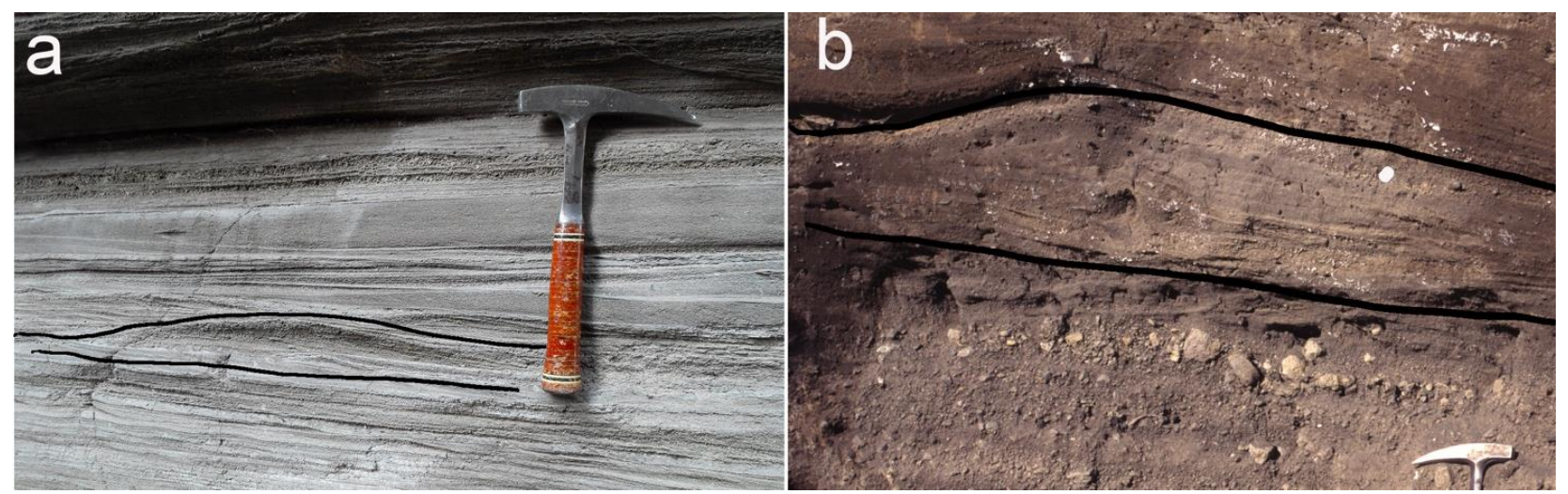

Fig. 2. PDC deposits showing bedforms. $a=$ ripples of PDC deposits at Vulcano. The curves enclose a ripple with $W_{l}=$ $40 \mathrm{~cm} . b=a$ dune bedform of PDC deposits at Vesuvius. The curves enclose a dune with $W_{l}=200 \mathrm{~cm}$. 
We never found antidunes, in fact their interpretation has always been questioned in volcanic $\operatorname{deposits}^{11,27}$.

111 The software PYFLOW 2.0 by Dioguardi and Mele ${ }^{31}$ has been used to plot data in Fig 1. It was 112 implemented here so to obtain both the impact parameters of the current together with $S_{r w}$ and $Q_{b}$. 113 The software employs sediment data that result from time-consuming laboratory analyses, which 114 involve technologies and calculation resources not available to all scientists (see the Method section). 115 The aim of this paper is to rearrange and simplify the dataset in order to construct a phase diagram by which to invert $W_{l}$ and $D$ of PDCs' deposits bedforms and obtain the impact parameters directly in the field, without the need of the extra terms that require extensive work in the laboratory. By means of regression analysis we obtained three fitting laws (Fig. 3a, b and c) that correlate just few of the many terms of the formulas of (5), (6) and (7) $\left(u_{*}^{2} C / Q_{b}, D^{0.5} u_{*} / u_{*}{ }^{2} C, u_{*}{ }^{0.4} C^{0.62} / S_{r w}\right.$, respectively), thus reducing the complexity of the original equations, and still guarantee high models.
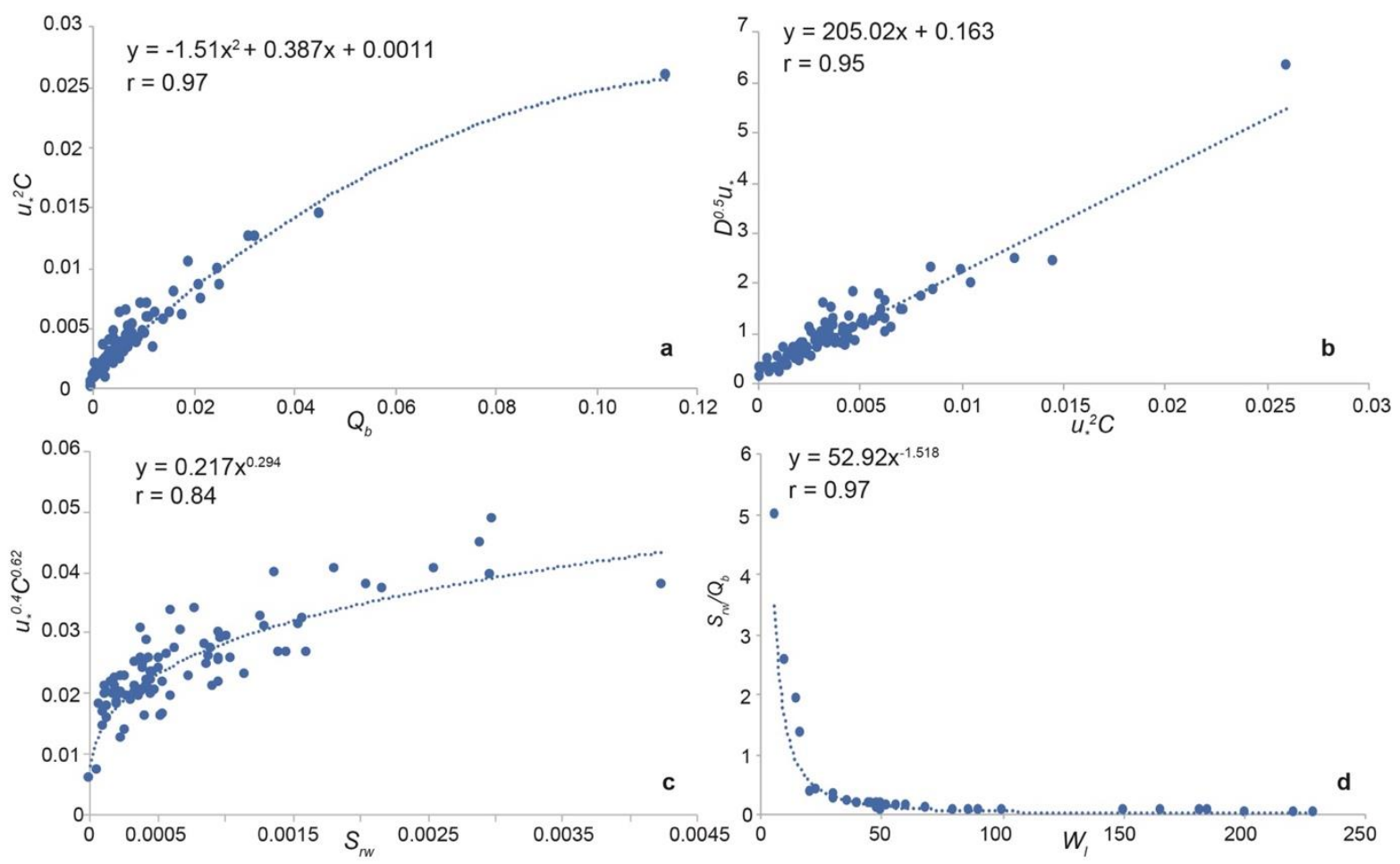

Fig. 3. Fits resulting from the regression analysis. In the insets both the correlation coefficient, $r$, and the fitting equation relationship between $u_{*}{ }^{0.4} C^{0.62}$ and $S_{r w .} d=$ power-law relationship between $S_{r w} / Q_{b}$ and $W_{l}$. 
128 A fourth fitting law between $S_{r w} / Q_{b}$ vs $W_{l}$ with a good correlation was obtained by selecting 32 129 deposits characterized by well exposed bedforms ranging between ripples and dunes (Fig. 3d).

130 The fitting laws allow interpreting $Q_{b}$ and $S_{r w}$ in terms of the deposit formation processes, and also to 131 relate them to the current's flow parameters. In Fig. 3a a relationship between $Q_{b}$ and $C u_{*}^{2}$ is shown. 132 Since $C$ is directly proportional to $\rho_{\text {mix }}$ and $\rho_{\text {mix }} u_{*}{ }^{2}$ is the turbulent shear stress of the current ${ }^{32}$, it 133 means that $Q_{b}$ is proportional to the shear stress, which confirms the finding of sedimentary currents ${ }^{29}$. 134 The relationship between $D u_{*}$ and $C u_{*}^{2}$ of Fig. $3 \mathrm{~b}$ implies that shear stress is proportional to bedforms 135 grain size, confirming what reported for sedimentary deposits ${ }^{28}$. On Fig. $3 \mathrm{c}$ a relationship between 136 the product of $C^{0.62} u_{*}^{0.4}$ and $S_{r w}$ is shown. Since the exponents of $C$ and $u_{*}$ are both lower than 1 , 137 while in the fitting with $Q_{b}$ of Fig. 3a they are 1 and 2 respectively, it means that with an increase of $138 C$ and $u_{*}$ the difference between $S_{r}$ and $Q_{b}$ increases, and $S_{r w} / Q_{b}$ decreases. This justifiesthat with the 139 decrease of $S_{r w} / Q_{b}$, the bedform wavelength increases continuously, as it is shown by Fig. 3d. This 140 outcome deserves an additional comment, because in sedimentary deposits ripples and dunes are not 141 believed to represent a continuum, being them separate by a hydrodynamic discontinuity ${ }^{33}$. This 142 happens because ripples, being small, do not interfere with the upper current surface, while dunes, 143 being larger, interfere with it. This discontinuity does not appear in the $S_{r w} / Q_{b}$ vs $W_{l}$ diagram of Fig. $1443 \mathrm{~d}$, likely because a true interface between the current and the surrounding atmosphere does not exist 145 in PDCs, which are instead characterized by a very gradual passage between the two ${ }^{10}$ (see the method 146 section for our model of dilute PDCs).

147 The four fitting laws make up a system of equations

$148 u_{*}^{2} C=1.5099 Q_{b}^{2}+0.3874 Q_{b}+0.0011$

$149 \quad D^{0.5} u_{*}=205.02 u_{*}^{2} C+0.163$

$u_{*}^{0.4} C^{0.62}=0.2168 S_{r}^{0.2938}$

$S_{r w} / Q_{b}=52.92 W_{l}^{-1.518}$ 
that can be solved numerically, once $D$ and $W_{l}$ are specified, to obtain $u_{*}, C, S_{r w}$ and $Q_{b}$. Important information on the hazard of dilute PDCs can be obtained from the first three parameters. $C$ and $u_{*}$ serve for the calculation of $P_{d y n}$ (2), since $C$ is used for obtaining $\rho_{\text {mix }}$ in (2) by means of (1) and $u_{*}$ is used for the calculation of $V$ by means of the law of the wall of a turbulent boundary layer ${ }^{32}$

$V(y)=u_{*}\left(\frac{1}{k} \ln \frac{y}{k_{s}}+8.5\right)$

which is the physical model of PDCs that we employ (see the method section), where $V(y)$ is the velocity profile of the stratified flow ${ }^{32}$, and $k_{s}$ is the substrate roughness.

When comparing results obtained by (8) with those resulting from PYFLOW 2, the average absolute error of $u_{*}$ is $28 \%$ and that of $C$ is $30 \%$. This means that a good approximation can be achieved for exploring the range of impact parameters by means of the simplified formulas, without the terms that involve extensive laboratory analysis.

The absolute error of $S_{r w}$ is about $45 \%$. While it is larger than that of $u_{*}$ and $C$, we discuss also the role of $S_{r w}$ because it allows the calculation of flow duration, $t^{15}$, which is an important factor of hazard. The total time of aggradation is a proxy of flow duration, $t$, which is equal to deposit thickness, $H_{d e p}$, divided by $A_{r}$, the aggradation rate. Sedimentation occurs by continuous aggradation during the passage of the current, and $A_{r}$ is equal to $S_{r w}$ divided by one meter, which is the reference width of the sedimentation rate per unit width, (see Dellino et al. ${ }^{28}$ ). Therefore, flow duration, which approximates the time in which harmful concentrations of ash are suspended in the current to which a human being can be exposed, can be calculated by means of $S_{r w}$. With our model a reasonable approximation can be achieved also on such a relevant parameter of PDCs.

In Fig. 4, which was constructed by means of (8), the main flow variables and impact parameters are 173 shown as a function of $D$ and $W_{l}$. The $W_{l}$ range was set between 10 and $300 \mathrm{~cm}$. Bedforms with larger $174 W_{l}$ can be found in the geologic record of volcanic deposits, but this scenario is out of the range of applicability of our model. We are, in fact, considering bedforms that develop on an almost flat surface. Much larger bedforms, instead, typically develop as an interplay between the current's flow 
dynamics and large ground morphology elements ${ }^{27}$ (e.g. ridges, big obstacles). The range of $D$ of Fig.

1784 was set between 4 and -2 phi ( $0.0064 \mathrm{~mm}$ and $4 \mathrm{~mm}$ respectively). We do not include coarser values 179 because, in volcanic sediments, larger sizes (coarse lapilli and bombs) do not form dunes, but 180 lenticular beds representing highly concentrated traction-carpets at the base of PDCs ${ }^{34,35}$, to which 181 our model does not apply.
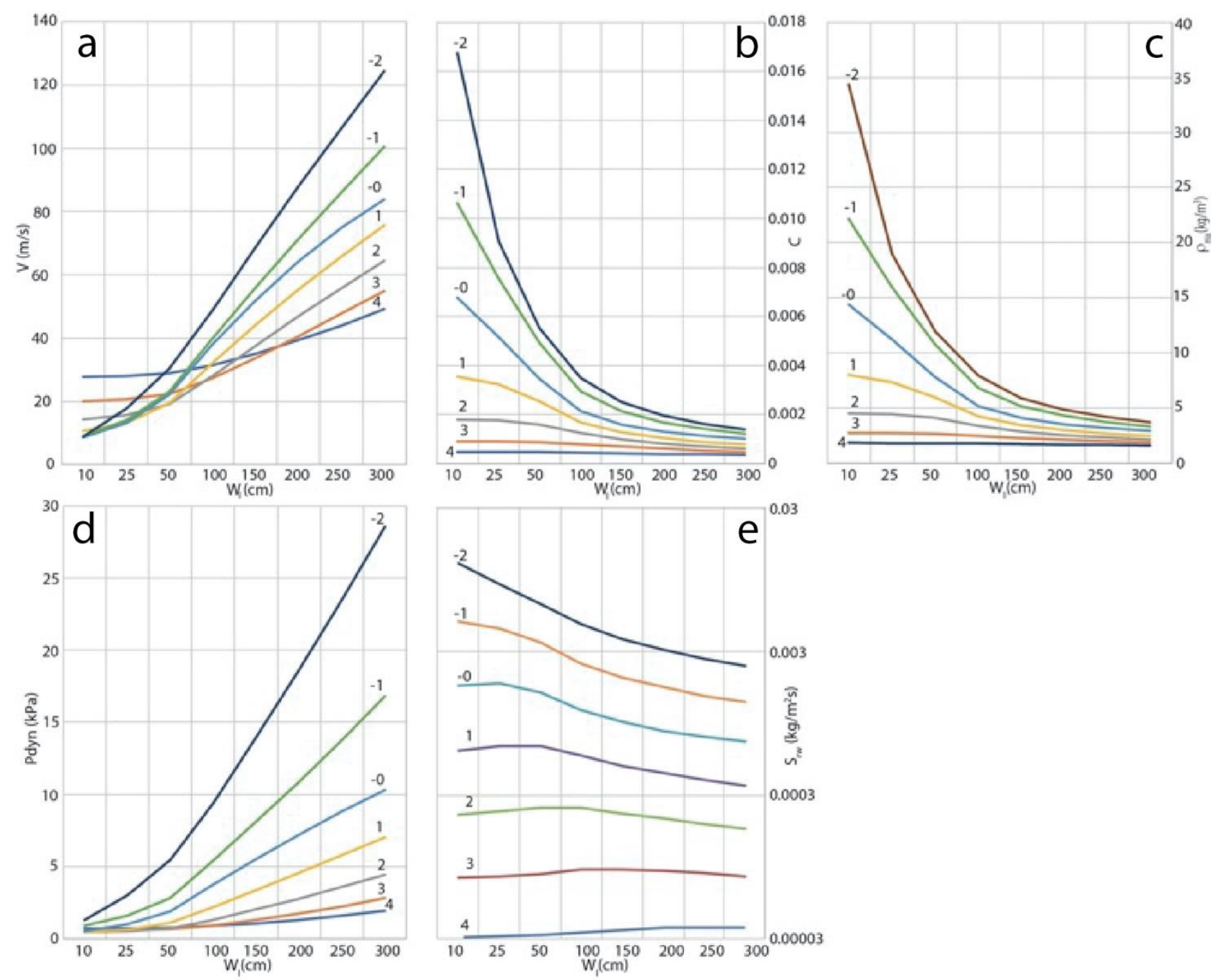

Fig. 4. Trends of flow variables and impact parameters of dilute PDCs as a function of bedform wavelengths. The various curves represent the behavior of different grain size D. Grain size is expressed in phi units ( $p h i=-\log _{2} D$, with D in mm). $a=$ trend of velocity, $V$, height-averaged in the first $1000 \mathrm{~cm}$ of the current in relation to $W_{l} . b=$ trend of concentration $C$, in relation to $W_{l} . c=$ trend of gas-particle mixture density $\rho_{\text {mix }}$, in relation to $W_{l}$. $d=$ trend of dynamic pressure, $P_{d y n}$ in relation to $W_{l}$. e =trend of sedimentation rate $S_{r w}$, in relation to $W_{l}$.

In Fig. 4a the value of velocity $V$, as averaged in the first $1000 \mathrm{~cm}$ of the current, which was obtained by integrating (9) over flow height, with $\mathrm{k}_{\mathrm{s}}=10 \mathrm{~cm}$, is plotted against $W_{l}$. We chose this depthaveraging height because, in dilute PDCs, the portion responsible for the dynamic impact is the 
lowermost one (the shear flow) and $1000 \mathrm{~cm}$ represent a reasonable estimate of an average building 193 height ${ }^{36} . V$ increases at increasing $W_{l}$ but with different trends and rates depending on the particle grain size $D$. In the diagram it ranges from about $10 \mathrm{~m} / \mathrm{s}$ to about $130 \mathrm{~m} / \mathrm{s}$. The trends are significantly different for the finer grain sizes ( 1 to 4 phi) at the smallest $W_{l}$ (up to $50 \mathrm{~cm}$ ), which can be interpreted as the smaller it is $W_{l}$, the smaller are $Q_{b}$ and shear stress, therefore the higher the velocity required to develop bedforms with the finest $D$. This is because for fine ash, due to the very low $R e_{*}$, the initiation of motion at the bedload occurs at a very high $\theta_{t}{ }^{29,37}$. With larger $W_{l}$, corresponding to larger $Q_{b}$ and larger shear stress, higher velocities are needed with coarser particles, because $\theta_{t}$ decreases down to the constant value characteristic of high $R e_{*}{ }^{37}$, which in turn implies that a larger shear stress is needed to move larger grain sizes. The volumetric concentration, $C$, ranges from less than 0.001 to about 0.017 (Fig. 4b). It decreases as $W_{l}$ increases, and it does so for all grain sizes, although at a rate that decreases at decreasing $D$, because a higher concentration favors a higher $S_{r w}$ (see (7)) and a larger $S_{r w} / Q_{b}$ ratio, hence a smaller $W_{l}$. The evident change in trend with decreasing grain size can be explained by the fact that the finer the particles, the lower the concentration required to develop bedforms with small wavelengths; the increase of shear stress and $Q_{b}$ results in similar concentrations for all grainsizes. The density of the current (Fig. 4c) follows the trend of concentration, as it is calculated by means of (1) and fixing $\rho_{s}=2000 \mathrm{~kg} / \mathrm{m}^{3}$ and $\rho_{f}=0.9 \mathrm{~kg} / \mathrm{m}^{3}$ (which is reasonable if the fluid, made up of volcanic gas plus entrained cold atmosphere, is at about $200{ }^{\circ} \mathrm{C}$ ${ }^{18}$ ) and varies from less than $2 \mathrm{~kg} / \mathrm{m}^{3}$ to about $35 \mathrm{~kg} / \mathrm{m}^{3}$. By using the values of density and velocity in (4) the trend of $P_{d y n}$ is shown in Fig. 4d. It varies from less than $1 \mathrm{kPa}$ with smaller $W_{l}$ and finer $D$, 212 which is a value that does not cause severe damages to buildings ${ }^{1,13}$, to almost $30 \mathrm{kPa}$ with larger $W_{l}$ and coarser $D$, which can destroy even the more resistant, modern buildings of reinforced concrete ${ }^{1,13}$. 214 The sedimentation rate (Fig. 4e) increases as grain size coarsens, meaning that with finer sizes flow 215 duration is longer, as it is expected since finer sizes result in a smaller settling velocity. As far as the wavelength is concerned, for the finest sizes, $S_{r w}$ increases at increasing $W_{l}$, meaning a decrease of 
217 flow duration with longer bedforms. With the coarsest sizes, instead, the sedimentation rate decreases 218 as $W_{l}$ increases, meaning a longer flow duration with longer bedforms.

219 The ranges of $W_{l}$ and $D$ used in (8) for obtaining the trends of Fig. 4 replicate the ranges in our dataset, 220 and result in parameters that span from currents that do not impact severely on structures, to values 221 of devastating effects. Such a range well represents the situation of large-scale PDCs whose strength 222 decreases along runout ${ }^{15}$, and change from totally destructive flows around the volcano to residual 223 currents that in the distal outreach do not possess a high strength but can still be rich of ash. Such fine 224 glassy material can be highly dangerous to breath even at concentrations lower than $0.001^{38}$ if flow 225 duration $t$, which can be calculated by means of $S_{r w}$, lasts more than a couple of minutes. Thus, with 226 our model it is possible to invert bedforms of past eruptions, and follow the different aspects of PDCs 227 hazard as they evolve along flow runout.

228 In order to help scientists not availing of numerical resources to take advantage of our results, we 229 solved (8) at discrete intervals of $D$ and $W_{l}$ and constructed a phase diagram where the stability fields 230 of $P_{d y n}, C$ and $S_{r w}$ are represented inside a grid (Fig. 5). The values are averaged among the four 231 neighboring grid points and the uncertainty is expressed in terms of one standard deviation. $P_{d y n}$ is 232 calculated by considering the average value obtained by integration over the first $1000 \mathrm{~cm}$ of the 233 current, and setting $k_{s}=10 \mathrm{~cm}$ and $\rho_{s}=2000 \mathrm{~kg} / \mathrm{m}^{3}$. 
Grain size $(\phi)$

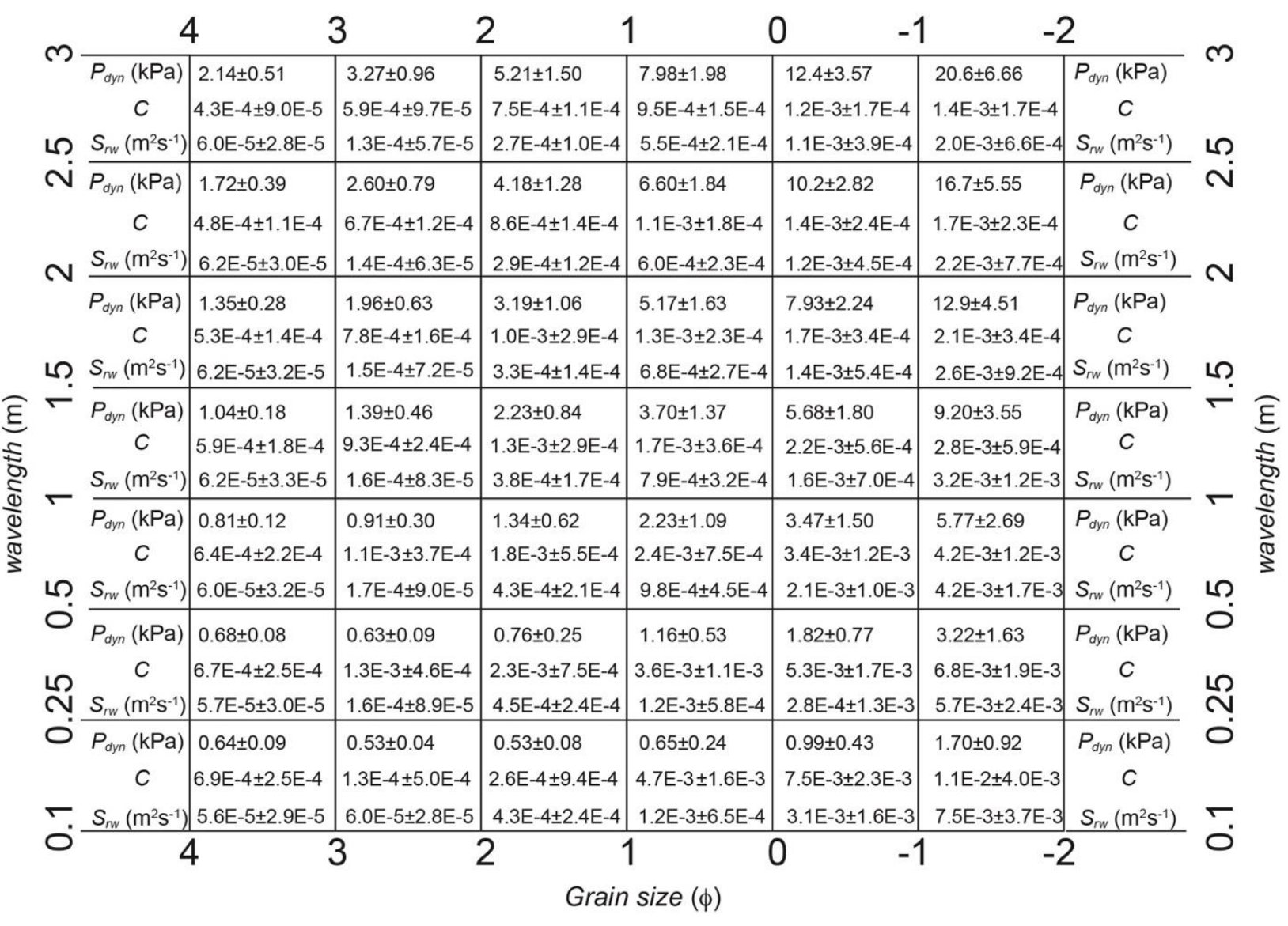

Fig. 5. Phase diagram in which the stability fields of the impact parameters $P_{d y n}, C$ and $S_{r w}$, are expressed as a function of $W_{l}$ and $D$ of bedforms. The values inside the grid represent the average between the four neighboring grid points and the uncertainty is expressed as the standard deviation. $K s=10 \mathrm{~cm}, \rho_{s}=2000 \mathrm{~kg} / \mathrm{m}^{3}$.

239 In the supplementary Information, additional diagrams with $k_{s}=10 \mathrm{~cm}$ and $\rho_{s}=1000 \mathrm{~kg} / \mathrm{m}^{3} ; k_{s}=30$ $\mathrm{cm}$ and $\rho_{s}=2000 \mathrm{~kg} / \mathrm{m}^{3}$; and $k_{s}=10 \mathrm{~cm}$ and $\rho_{s}=1000 \mathrm{~kg} / \mathrm{m}^{3}$ are included (Supp. Fig. 1,2 and 3 respectively), and a table is also provided (Supp. Tab.1) where the values of $u_{*}, C$ and $S_{r}$ are set at half phi intervals of $D$ in relation to $W_{l}$. By means of these data, and specifying in (4) and (9) the value of $k s, \rho_{s}$, and $H$ at which to integrate $V$, more precise data of the impact parameters can be obtained.

245 With our diagrams and tables at hand it is thus possible for every scientist working on hazardous volcanoes to make an exploratory hazard assessment by means simply of the wavelength and grain size of bedforms. It is true that bedforms are not always well exposed in their complete longitudinal profile, because of truncations due to erosion. Sometimes they are also difficult to measure precisely, 
because a direct access to the deposit is hard. Anyway, our experience tells that dilute PDCs most always leave well-preserved bedforms as a trace of their passage. Scientists working on active volcanoes are encouraged to look for good outcrops where bedforms can be measured. By means of our phase diagrams, now they have a tool for exploring the behavior of hazardous pyroclastic density currents directly in the field.

\section{Method}

The reconstruction of the impact parameters of PDCs is based on a flow mechanical model that starts with the assumption that the turbulent current is velocity and density stratified ${ }^{12,40}$. In the stratified multiphase gas-particle current, the basal part is a shear flow that moves attached to the ground and has a density higher than atmosphere (Fig. 6). The upper part is buoyant, because particle concentration decreases with height down to a value that, combined with the effect of gas temperature, makes the mixture density lower than the surrounding atmosphere.

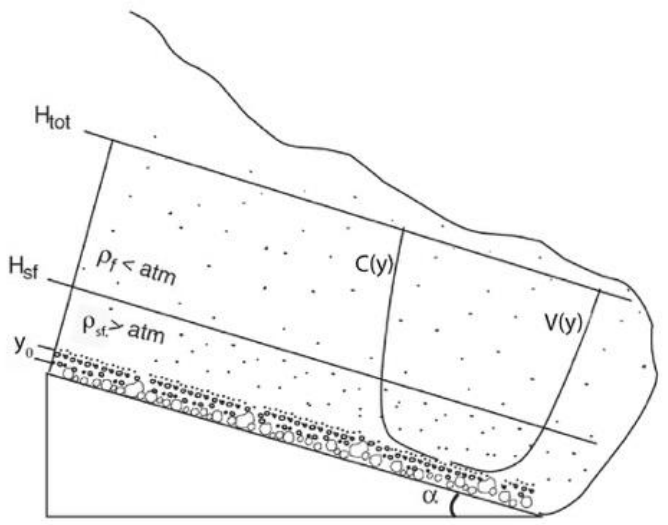

Fig. 6. Skecth of the model of a pyroclastic density current used in this paper

In a PDC, particles are mainly transported by turbulent suspension and sedimentation is controlled by a balance between flow shear velocity $u *$, which is controlled by fluid turbulence and favors suspension, and particle settling velocity, $w_{t}=\left(4 g D\left(\rho_{s}-\rho_{\text {mix }}\right) / 3 C_{d} \rho_{m i x}\right)^{0.5}$, which favors sedimentation, where $C_{d}$ is drag coefficient. During sedimentation, it is assumed that particles of different composition, i.e. crystals and glass, settle at the same aerodynamic conditions, e.g., with the same 
terminal velocity ${ }^{15}$. Therefore, by equating the settling velocity of the glass and crystal components

271 in the deposit, and assuming that sedimentation starts when $P_{n}=2.5$, hence when $w_{t}=u *$, flow shear velocity and density $\rho_{s f}$ of the shear flow can be calculated after $D, \rho_{s}$ and $C_{d}$ are measured in the 273 laboratory ${ }^{36}$. These are the main input data in the PYFLOW_2.0 code $^{31}$, which allows reconstructing 274 the current parameters.

275 The code is based on a model that assumes PDCs behave as turbulent boundary layer shear flows moving over a rough surface ${ }^{37}$, which velocity profile is given by (9). The model has been validated by experiments ${ }^{18}$ and already applied to other eruptions $s^{40,41}$. Here it is summarized as adapted from 278 Dellino et al. ${ }^{15}$.

279 The maximum volumetric concentration of particles that can be transported in turbulent suspension, 280 i.e. the maximum current capacity, is a function of the Rouse number of the particulate mixture taken 281 in suspension. The profile of volumetric concentration over current height is regulated by the Rouse 282 model $^{42}$.

$C(y)=C_{0}\left(\frac{y_{0}}{H-y_{0}} \frac{H-y}{y}\right)^{P_{n}}(10)$

284 where $C_{0}$ is the particle volumetric concentration at a reference height $y_{0}$ and $H$ is the total current 285 thickness. Assuming steady sedimentation, $H$ is obtained by the ratio $H_{d e p} / C_{s f}$ where $H_{d e p}$ is deposit 286 thickness and $C_{s f}$ is the depth-averaged concentration in the basal shear flow, which can be calculated 287 by $\rho_{s f}=\rho_{s} C_{s f}+\rho_{f}\left(1-C_{s f}\right)$, when $\rho_{s f}$ and $\rho_{f}$ are known.

288 The shear-flow height and density are obtained by solving the system of (11) and (12), which is valid 289 for a turbulent current

$290 \tau=\left(\rho_{s f}-\rho_{f}\right) g \sin \alpha H_{s f}(11)$

$291 \tau=\rho_{s f} u_{*}^{2}(12)$

292 where $\tau$ is the shear-driving stress of the flow moving down an inclined slope of angle $\alpha$.

293 The density profile, which is a function of concentration, particle density and gas density, is:

$\rho_{\text {mix }}(y)=\rho_{f}+C_{0}\left(\frac{y_{0}}{H-y_{0}} \frac{H-y}{y}\right)^{P_{n}}\left(\rho_{s}-\rho_{f}\right)(13)$ 
The gas density and Rouse number are obtained by solving numerically the following system:

$\rho_{a}(y)=\rho_{f}+C_{0}\left(\frac{y_{0}}{H-y_{0}} \frac{H-H_{s f}}{H_{s f}}\right)^{P_{n}}\left(\rho_{s}-\rho_{f}\right)(14)$

$\rho_{s f}=\frac{1}{H_{s f}-y_{0}} \int_{y_{0}}^{H_{S f}}\left(\rho_{f}+C_{0}\left(\frac{y_{0}}{H-y_{0}} \frac{H-y}{y}\right)^{P_{n}}\left(\rho_{s}-\rho_{f}\right)\right) d y(15)$

Equation (14) states that atmospheric density, $\rho_{a}$, is reached at the top of the shear flow, $H_{s f}$, and equation (15) states that the average density of the shear flow, $\rho_{s f}$ refers to the part of the flow that goes from the reference level, $y_{0}$, to the shear flow top height, $H_{s f}$.

By combining the velocity and density profiles, the dynamic pressure profile is finally obtained. The profiles of the flow parameters are expressed in terms of a probability density function that depends on the variance of particle characteristics.

\section{References}

1. Spence, R. J.S., Baxter, P. J. \& Zuccaro G. Building vulnerability and human casualty estimation for a pyroclastic flow: A model and its application to Vesuvius. J. Volcanol. Geotherm. Res. 133, 321- 343 (2004).

2. Sulpizio, R., Dellino, P., Doronzo, D. M. \& Sarocchi, D. Pyroclastic density currents: state of the art and perspectives. J. Volcanol. Geotherm. Res. 283, 36-65 (2014).

3. Chough, S.K. \& Sohn, Y.K. Depositional mechanics and sequences of base surges, Songaksan tuff ring, Cheju Island, Korea. Sedimentology 37(6), 1115-1135 (1990).

4. Douillet, G.A. The supercritical question for pyroclastic dune bedforms: An overview. Sedimentology (2021). doi.org/10.1111/sed.12859

5. Middleton, G.V. \& Southard, J.B. Mechanics of Sediment Movement, 2nd edn. Society of Economic Paleonologists and Mineralogists, Tulsa, OK, 401 pp (1984).

6. Bartholdy, J., Ernstsen, V.B., Flemming, B.W., Winter, C., Bartholomä, A. \& Kroon, A. On the formation of current ripples. Sci. Rep. 5, 11390 (2015). doi:10.1038/srep11390

7. Ashley, G.M. Classification of large-scale subaqueous bedforms: a new look at an old problem: bedforms and bedding structures: J. Sed. Pet. 60, 160-172 (1990).

8. Perillo, M.M., Best, J.L. \& Garcia, M.H. A new phase diagram for combined-flow bedforms. J. Sed. Res. 84, 301-313 (2014).

9. Fedele, J.J., Hoyal, D.C., Barnaal, Z., Tulenko, J. \& Awalt, S. Bedforms created by gravity flows. In: In: Budd, D., Hajek, E., Purkis, S. (Eds.), Autogenic Dynamics and SelfOrganization in Sedimentary Systems 106. SEPM Spec. Pub. 95-121 (2016).

10. Middleton, G.V. (1993). Sediment deposition from turbidity currents. Annu. Rev. Earth Planet. Sci. 21, 89-114 (1993).

11. Allen J.R.L. Sedimentary Structures, their Character and Physical Basis. Developments in Sedimentology, vol. 30A, Elsevier (1982).

12. Valentine, G.A. Damage to structures by pyroclastic flows and surges, inferred from nuclear weapons effects. J. Volcanol. Geoth. Res. 87, 117-140 (1998). 
13. Zuccaro, G., Cacace, F., Spence, R.J.S. \& Baxter, P.J. Impact of explosive eruption scenarios at Vesuvius. J. Volcanol. Geotherm. Res. 178, 416-453 (2008).

14. Baxter, P.J., Jenkins, S., Rosadi, S., Komorowski, J.-C., Dunn, K., Purser, D., Voight, B. \& Shelley, I. Human survival in volcanic eruptions: thermal injuries in pyroclastic surges, their causes, prognosis and emergency management. Burns 43, 1051-1069 (2017).

15. Dellino P., Dioguardi F., Isaia R., Sulpizio R., Mele D. The impact of pyroclastic density currents duration on humans: the case of the AD 79 eruption of Vesuvius. Sci. Rep. 11(1), 4959 (2021).

16. Branney, M.J. \& Kokelaar, P. Pyroclastic density currents and the sedimentation of ignimbrites. Geol Soc London Memoir 27, 1-143 (2002).

17. Smith, G., Rowley, P., Williams, R., Giordano, G., Trolese, M., Silleni, A., Parsons, D.R. \& Capon, S. A bedform phase diagram for dense granular currents. Nat. Commun. 11(1), 1-11 (2020).

18. Dellino, P., Büttner, R., Dioguardi, F., Doronzo, D.M., La Volpe, L., Mele, D., Sonder, I., Sulpizio, R. \& Zimanowki, B. Experimental evidence links volcanic particle characteristics to pyroclastic flow hazard. Earth Planet. Sci. Lett. 295, 314-320 (2010). doi: 10.1016/j.epsl.2010.04.022

19. Andrews, B.J. Recognizing unsteadiness in the transport systems of dilute pyroclastic density currents. Bull. Volcanol. 81(2), 5 (2019).

20. Brosch, E. \& Lube, G. Spatiotemporal sediment transport and deposition processes in experimental dilute pyroclastic density currents. J. Volcanol. Geotherm. Res. 401, 106946 (2020).

21. Doronzo, D.M., Dellino, P., Sulpizio, R., Lucchi, F. Merging field mapping and numerical simulation to interpret the lithofacies variations from unsteady pyrolcastic density currents on uneven terrain: The case of La Fossa di Vulcano (Aeolian Islands, Italy). J. Volcanol. Geotherm. Res. 330, 36-42 (2017).

22. Tadini, A., Bevilacqua, A., Neri, A., Cioni, R., Biagioli, G., de'Michieli Vitturi, M., Esposti Ongaro, T. Reproducing pyroclastic density current deposits of the 79 CE eruption of the Somma-Vesuvius volcano using the box-model approach. Solid Earth 12, 119-139 (2021).

23. Doronzo, D.M., de Tullio, M.D., Pascazio, G., Dellino, P., Liu, G. On the interaction between shear dusty currents and buildings in vertical collapse: Theoretical aspects, experimental observation, and 3D numerical simulation. J. Volcanol. Geotherm. Res. 302, 190-198 (2015).

24. Richards, A.F. Geology of the islas revillagigedo, mexico. Bull. Volcanol. 22(1), 73 (1959).

25. Moore, J.G. Base surge in recent volcanic eruptions. Bull. Volcanol. 30(1), 337 (1967).

26. Fisher, R.V. \& Waters, A.C. Bed forms in base-surge deposits: Lunar implications. Science 165(3900), 1349-1352 (1970).

27. Douillet, G.A., Bernard, B., Bouysson, M., Chaffaut, Q., Dingwell, D.B., Gegg, L., Hoelscher, I., Kueppers, U., Mato, C., Ritz, V.A. \& Schlunegger, F. Pyroclastic dune bedforms: macroscale structures and lateral variations. Examples from the 2006 pyroclastic currents at Tungurahua (Ecuador). Sedimentology 66(5), 1531-1559 (2019).

28. Dellino, F., Dioguardi, F., Doronzo, D.M. \& Mele, D. A discriminatory diagram of massive vs stratified deposits based on the sedimentation and bedload transportation rates. Experimental investigation and application to pyroclastic density currents. Sedimentology 67 (4), 2013-2039 (2020). doi:10.1111/sed.12693.

29. Dellino, P., Dioguardi, F., Doronzo, D.M. \& Mele, D. The rate of sedimentation from turbulent suspension: an experimental model with application to pyroclastic density currents and discussion on the grain-size dependence of flow mobility. Sedimentology 66(1), 129-145 (2019). doi:10.1117sed.12485.

30. Wilcock, P.R. \& Crowe, J.C. Surface-based transport model for mixed-size sediment. J. Hydraul. Eng. 129, 120-128 (2003). 
31. Dioguardi, F. \& Mele, D. PYFLOW_2.0: A computer program for calculating flow properties and impact parameters of past dilute pyroclastic density currents based on field data. Bull. Volcanol. 80(3), 28 (2018). doi:10.1007/s00445-017-1191-z.

32. Furbish, D.J. Fluid Physics in Geology. Oxford University Press, New York, Oxford. 476 pp (1997).

33. de Cala, I., Ohata, K., Dorrell, R., Naruse, H., Patacci, M., Amy, L.A., Simmons, S., McLelland, S.J. \& McCaffrey, W.D. Relating the Flow Processes and Bedforms of SteadyState and Waning Density Currents. Front. Earth Sci. 8, 535743 (2020). doi: 10.3389/feart.2020.535743.

34. Sohn, Y.K. On traction-carpet sedimentation. J. Sed. Res. 67, 502-509 (1997).

35. Dellino, P., Isaia, R., La Volpe, L. \& Orsi, G.. Interaction between particles transported by fallout and surge in the deposits of the Agnano-Monte Spina eruption (Campi Flegrei, Southern Italy). J. Volcanol. Geotherm. Res. 133, 193-210 (2004).

36. Dellino, P., Mele, D., Sulpizio, R., La Volpe, L. \& Braia, G. A method for the calculation of the impact parameters of dilute pyroclastic density currents based on deposit particle characteristics. J. Geophys. Res. 113, B07206 (2008). doi:10.1029/2007JB005365.

37. Miller, M.C., McCave, I.N. \& Komar, P.D. Threshold of sediment motion under unidirectional currents. Sedimentology 24, 507-527 (1977).

38. Jenkins, S., Komorowski, J.C., Baxter, P.J., Spence, R., Picquout, A., Lavigne, F. \& Surono. The Merapi 2010 eruption: An interdisciplinary impact assessment methodology for studying pyroclastic density current dynamics. J. Volcanol. Geotherm. Res. 261, 316-329 (2013).

39. Brown, R.J. \& Branney, M.J. Internal flow variations and diachronous sedimentation within extensive, sustained, density stratified pyroclastic density currents down gentle slopes, as revealed by the internal architectures of ignimbrites in Tewnerife. Bull. Volcanol. 75, 1-24 (2013).

40. Dellino, P., Mele, D., Bonasia, R., Braia, G., La Volpe, L. \& Sulpizio, R. The analysis of the influence of pumice shape on its terminal velocity. Geophys. Res. Lett. 32, L21306 (2005).

41. Mele, D., Dioguardi, F., Dellino, P., Isaia, R., Sulpizio, R. \& Braia, G. Hazard of pyroclastic density currents at the Campi Flegrei Caldera (Southern Italy) as deduced from the combined use of facies architecture, physical modeling and statistics of the impact parameters. $J$. Volcanol. Geotherm. Res. 299, 35-53 (2015).

42. Rouse, H. An analysis of sediment transportation in the light of fluid turbulence. Soil Conservation Services Report No. SCS-TP-25, USDA, Washington, D.C (1939). 


\begin{tabular}{|c|c|c|}
\hline Symbol & description & dimension \\
\hline$A_{r}$ & Aggradation rate per unit width & $\mathrm{ms}^{-1}$ \\
\hline$C$ & Particle volumetric concentration & - \\
\hline$C_{0}$ & Reference known concentration $(0.75)$ & - \\
\hline$C_{s f}$ & Depth-averaged concentration in the basal shear flow & - \\
\hline$C_{d}$ & Particle drag coefficient & - \\
\hline$D$ & Sediment median size & $\mathrm{mm}$ \\
\hline$F r^{\prime}$ & Froude number & \\
\hline$g$ & Gravity acceleration (9.81) & $\mathrm{ms}^{-2}$ \\
\hline$H$ & Current depth & $\mathrm{cm}$ \\
\hline$H_{\text {dep }}$ & Deposit thickness & $\mathrm{cm}$ \\
\hline$k$ & Von Karman constant $(0.4)$ & - \\
\hline$k_{s}$ & Substrate roughness & $\mathrm{cm}$ \\
\hline$P_{d y n}$ & Dynamic pressure & $\mathrm{Pa}$ \\
\hline$P_{n}$ & Particle Rouse number & - \\
\hline$P_{n}^{*}$ & Normalized Rouse number & - \\
\hline$P_{\text {navg }}$ & Average Rouse number of solid material & - \\
\hline$P_{n i}$ & Rouse number of the ith particle-size class & - \\
\hline$P_{\text {nsusp }}$ & Rouse number at maximum suspension capacity & - \\
\hline$Q_{b}$ & Bedload transportation rate & $\mathrm{m}^{2} \mathrm{~s}^{-1}$ \\
\hline$q_{b i}$ & Volumetric bedload transport rate of the ith particle-size class & $\mathrm{m}^{2} \mathrm{~s}^{-1}$ \\
\hline$R e^{*}$ & Reynolds' number & - \\
\hline$S_{r}$ & Sedimentation rate & $\mathrm{kgm}^{-2} \mathrm{~s}^{-1}$ \\
\hline$S_{r w}$ & Sedimentation rate per unit width & $\mathrm{m}^{2} \mathrm{~s}^{-1}$ \\
\hline$t$ & Flow duration & s \\
\hline$u_{*}$ & Shear velocity & $\mathrm{ms}^{-1}$ \\
\hline$V$ & Current velocity & $\mathrm{ms}^{-1}$ \\
\hline$W_{i}^{*}$ & Dimensionless transport rate of the ith particle-size class & - \\
\hline$W_{l}$ & wavelength & $\mathrm{cm}$ \\
\hline$w_{t}$ & Particle terminal velocity & $\mathrm{ms}^{-1}$ \\
\hline$w_{t i}$ & Terminal velocity of the ith particle-size class & $\mathrm{ms}^{-1}$ \\
\hline$y$ & Flow vertical coordinate & $\mathrm{cm}$ \\
\hline$y_{0}$ & Specific height of $\mathrm{C}_{0}$ & - \\
\hline$\alpha$ & Slope angle & $\circ$ \\
\hline$\phi$ & Unit of grain-size distribution ( $\phi=-\log _{2} d$; $d$ is in $\mathrm{mm}$ ) & - \\
\hline$\phi_{i}$ & Weight fraction of the $i_{\text {th }}$ size class & Weight $\%$ \\
\hline$\theta_{t}$ & Shield's number & - \\
\hline$\mu$ & Fluid viscosity & Pas \\
\hline$\rho_{f}$ & Fluid density & $\mathrm{kgm}^{-3}$ \\
\hline$\rho_{m i x}$ & Density of the fluid-particle mixture & $\mathrm{kgm}^{-3}$ \\
\hline$\rho_{s}$ & Particle density & $\mathrm{kgm}^{-3}$ \\
\hline$\rho_{s f}$ & Density of shear flow & $\mathrm{kgm}^{-3}$ \\
\hline$\rho_{s i}$ & Density of the ith particle-size class & $\mathrm{kgm}^{-3}$ \\
\hline$\tau$ & Shear stress at the base of the current & $\mathrm{Pa}$ \\
\hline$\tau_{r i}$ & Minimum shear of the $i_{t h}$ size fraction & $\mathrm{Pa}$ \\
\hline$\xi$ & Normalized shear stress & - \\
\hline
\end{tabular}




\section{Supplementary Files}

This is a list of supplementary files associated with this preprint. Click to download.

- Suppfig1.pdf

- Suppfig2.pdf

- Suppfig3.pdf

- SupplTab.pdf 